\section{Research Square}

Preprints are preliminary reports that have not undergone peer review.

They should not be considered conclusive, used to inform clinical practice, or referenced by the media as validated information.

\title{
Epidemiology of Injury Among School-Going Adolescents in Ghana: Evidence From the Global School-Based Students Health Survey
}

\author{
Samuel Kwaku Essien \\ University of Saskatchewan College of Medicine \\ Batholomew Chireh \\ Saskatchewan Health Quality Council \\ Kidest Getu Melese ( $\square$ kidestgetu2006@gmail.com ) \\ Wolaita Sodo University https://orcid.org/0000-0002-6269-7793
}

\section{Original Contribution}

Keywords: Epidemiology, Unintentional injuries, Adolescents, School, Ghana

Posted Date: August 17th, 2020

DOI: https://doi.org/10.21203/rs.3.rs-53390/v1

License: (c) (i) This work is licensed under a Creative Commons Attribution 4.0 International License. Read Full License 


\section{Abstract}

Background: Unintentional injuries are a serious global public health problem and the second leading cause of death among adolescents age between 10-19 years. It is also the least researched in most low-income countries and Ghana in particular. This study aims to provide estimates of the prevalence, causes, and associated risk factors of unintentional injuries among school-going adolescents in Ghana.

Methods: This is a cross-sectional study using data from the Ghana Global School-based Student Health Survey conducted in 2012 (N=3632). A two-stage cluster probability sampling technique was employed to select a representative sample of Junior and Senior High School students in ten administrative regions of the country. Cross tabulations and chi-square tests were used to provide estimates of prevalence, frequency, and causes of injuries. In the multivariable stage, a multiple logistic regression based on SAS 9.4 survey logistic modeling procedure was conducted to examine the association between unintentional injuries with explanatory variables. The final adjusted model was assessed using a significant level of $(p<0.05)$.

Results: In this study, 40.96\% (1488) of school-aged adolescents reported having experienced an unintentional injury. Of these injuries, $64.5 \%$ occurred at home, while the least occurred via traffic (15.0\%). The frequency of injury did not differ between boys and girls $(P=0.368)$, but significantly higher in adolescents aged $\leq 17$ than in those $\geq 18$ years $(P<0.001)$. Also, injuries were significantly higher in junior high school than in senior high school adolescents. Age, physical activity, sleeping problems, and loneliness were found to be the significant risk factors associated with unintentional injury among adolescents.

Conclusion: Prevalence of unintentional injuries were widespread among adolescents in Ghana. Prompt prevention of these injuries among adolescents should be a public health priority. Preventive strategies in schools and homes should be enhanced. Injury preventive measures should emphasize on adolescents. Treatment options should be made available to adolescents struggling with a sleeping problem, loneliness, and those with accidents in physical activity.

\section{Introduction}

Injuries are defined as damage to a person caused by an acute transfer of mechanical, thermal, electrical, chemical, or radiation energy or by the sudden absence of heat or oxygen (WHO, 2008). Unintentional injuries consist of the subset of injuries for which there is no evidence of predetermined intent and include motor vehicle injuries, suffocation, drowning, poisoning, burns, falls, an accident on sports and recreational activities (e.g. sprains or strains) (Wu et al., 2019, Sleet, 2018).

Worldwide, unintentional injuries are a serious health problem (Han et al., 2019) and are the second leading cause of years lost due to disabilities for adolescents between the ages of 10-19 years (Gore FM, 2011). It is also one of the most common causes of death and school absenteeism among school-aged adolescents in developing countries (WHO, 2015). Across the globe, a higher prevalence of injuries among school-going adolescents has been observed. In the United States, 19 children age 1-19 die each day with unintentional injury. One in four children yearly will be injured seriously and fail to go to school or work or need medical attention or bed rest. In 2016, foreach unintentional injury loss to those ages 0-19 there were nearly 33 hospitalizations and 1053 emergency unit visits (CDC, 2018). The mean value of unintentional injury in low- and middle-income countries (LMICs) was 40\% (Street \& Jacobsen.,2016). Reports in Palestine (47.6\%) (Jildeh et al., 2013), Nigeria (73.6\%) (Azubuike and Onyemaka, 2012), and Malaysia (34.9\%) (Peltzer and Pengpid, 2015) are some of the examples from LMICs. About 10-25\% of injuries found in all children and adolescents, this all does happen on school premises (Posner, 2000, Sleet et al., 2010). Evidence suggests that the global burden of injuries is likely to witness a steady rise if measures are not put in place to prevent unintentional injuries (WHO, 2009). Unfortunately, awareness of the problem, the means to prevent it, and the political commitment to act remain unacceptably low. There is also a public health inequity in that the evidence base for unintentional injury prevention is limited especially in LMIC (WHO, 2015).

Despite the enormous burden unintentional injuries bring to societies, including high mortality (Shinsugi et al., 2015, Porter et al.,2019) and disability (WHO, 2018), some countries have adopted effective preventive measures to reduce these burdens (Orton et al.,2016, Salam et al., 2016). These measures included subsides on safety devices (e.g. safety helmets) (Ralaidovy et al., 2018, The Children's Safety Network and National Institute for Health Care Management, 2010). Training and education on the use of safety devices product (Salam et al., 2016), and environmental modifications, legislation or regulation on the use of safety devices, neuromuscular training, rule modification, and equipment recommendations (Emery and Pasanen, 2019). More importantly, expanding computer-based programmes which used for injury-prevention through education and behavioural change (Omaki et.al., 2017) and drink driving enforcement and speed enforcement (Vecino-Ortiz et.al., 2018). The influence of these preventive strategies on unintentional injury reduction was further confirmed in a recent systematic review on injury intervention programs and other studies that found a 1-34\% reduction unintentional injuries among adolescents owing to a successful implementation of prevention and intervention strategies (Vecino-Ortiz et.al., 2018, Salam et al., 2016).

In Ghana, the last population census organized in 2010 and published in 2012 showed an estimated total population of 24.6 million. Out of this number, adolescents of school-going age (10-19 years) constituted $22.4 \%$ (GSS, 2012). However, studies on the prevalence and potential risk factors for unintentional injury among Ghanaian school-going adolescents are scarce. To the authors' knowledge, no Ghanaian study explicitly 
explored the prevalence of unintentional injuries and their correlates among adolescents of school-going age and no known injury intervention programs exist in junior and senior high schools in the country. Therefore, a better understanding of the epidemiology of injury among adolescents of school-going age in Ghana would not only provide valuable information on the extent of injury in the countries educational sector but would help inform both prevention strategies and public policies. This study aimed to address this gap by investigating the prevalence and potential risk factors of unintentional injuries in school-aged adolescents in Ghana.

\section{Methods}

\section{Data Sources}

This study used data from the Ghana Global School-based Student Health Survey (GSHS) carried out in 2012 via collaboration among the World Health Organization (WHO), the United States Centers for Disease Control and Prevention (WHO,2020a), Middle Tennessee State University, and the Ghana Education Service (Owusu, 2008).

\section{Ghana Global School-based Student Health Survey}

This GSHS is a cross-sectional survey study design which was conducted primarily to examine health behaviors and protective factors among school-going adolescents in Ghana (Owusu, 2008, WHO, 2020b). The 2012 GSHS survey was an extension on an earlier 2008 GSHS survey where a two-stage cluster probability sampling method was employed to select a representative sample of Junior High School (grades 7-9, ages 10-15 years) and Senior High School (grades 10-12, ages 16-19 years) students in ten administrative regions within three zones in Ghana (South: Greater Accra, Central, Volta \&Eastern; Central: Brong Ahafo, Ashanti \&Western; and North: Northern, Upper East \&Upper West) (Owusu, 2008). In addition to seeking consent and protecting students' privacy, the questionnaire was first pilot tested in 2008 on twenty student samples to ensure the appropriateness of the design, questions, and wording (Owusu, 2008). To correct for any bias from non-responses and the varying probability of selection, a weighting factor accounting for each student demographic profile was applied (Owusu, 2008, WHO, 2012). A total of 3632 which include 1645 (45.3\%) Junior High School (JHS) students, 1972 (54.3\%) Senior High School (SHS) students, and 15 (0.4\%) missing data of school-aged adolescents were collected (WHO, 2020b). These resulted in an overall response rate of $82 \%$ at the JHS level and $71 \%$ at the SHS level (WHO, 2012).

\section{Measurements}

\section{Outcomes of interest}

In this study, three main outcomes of interest were considered, namely: injury status, injury frequency, and cause of injury. Injury status was categorized as "yes" or "no" based on the question: "during the past 12 months, what was the most serious injury that happened to you?". Participants were assigned "no" if they answered: "I was not seriously injured during the past 12 months" and "yes" if at least one injury was reported. Injury frequency was categorized into four groups: "zero', "one time", "two to three times" and "four or more times" based on the question "during the past 12 months, how many times were you seriously injured?". In addition, the cause of injury was also assessed with the question, "during the past 12 months, what was the major cause of the most serious injury that happened to you?". The responses were categorized as "traffic (e.g., motor vehicle accident/automobile crash)", "home" and "other" (Wu et al., 2019). Injuries such as falls, something fell/hit me, assault/abuse, flame/something hot, and poisoning that often happens in the home were defined in the current study as "home" injuries (Wu et al., 2019). Others consisted of those who indicate something else caused their injury.

\section{Other Factors}

A set of demographic factors including age ( $\leq 17$ and $\geq 18$ years), sex (boys/girls), educational level (JHS/SHS), and body mass index (BMI) were examined in relation to the outcomes of interest. BMI was calculated as weight per height square $\left(\mathrm{kg} / \mathrm{m}^{2}\right)$. School-aged adolescents with $\mathrm{BMI}$ values equal to adult BMI of $<18.5$ were classified as underweight, $18.5-24.9$ as normal, $25-29.9$ as pre-obese, and $\geq 30$ as obese (Cetin et al., 2016). Moreover, psychological distress factors such sleep-related problems (defined as reporting to the question "during the past 12 months, how often have you been so worried about something that you could not sleep at night?") (WHO, 2020b) and loneliness (defined as reporting to the question "during the past 12 months, how often have you felt lonely?") (WHO, 2020b) were considered for the study analysis. Both factors were assessed on the following scale: never, sometimes, and often. Furthermore, adolescent leisure-time physical activity assessed as: "during the past 7 days, how many days were you physically active for a total of at least 60 minutes per day?"(WHO, 2020b) with responses categorized as "none" and "at least a day".

\section{Statistical Analysis}

Chi-square tests (McHugh, 2013) were performed to assess differences in injury frequency and cause of injury by demographic factors among school-aged adolescents. Additionally, a multiple logistic regression based on SAS 9.4 surveylogistic modeling procedure was conducted to 
examine the association between injury status and the survey explanatory variables. The survey logistic method provided the opportunity to correct for complex survey design effects (e.g., clustering, stratum, and weighting) in the analysis (Agnelli, 2014). Also, this approach was chosen to fulfill the requirement outlined in the GSHS data user's guide that " all three variables (weight, stratum, and primary sampling unit (PSU)) are required to be used when analyzing GSHS data to appropriately represent the weighting process and the two-stage sample design" (WHO, 2013). All demographic, psychological distress, and adolescent leisure-time physical activity factors were screened by examining the unadjusted associations with injury status. All factors with p-values < 0.25 (Hosmer et al., 2000) were included in the final adjusted model. The final adjusted model was fitted from the significant main effect(s) $(p<0.05)$ by eliminating the highest $p$-values to the lowest via manual backward elimination method (Hosmer et al., 2000). Furthermore, Receiver Operating Characteristic (ROC) (Allison, 2012) curves were used to examine and compare the predictive power between the model with only 'sleep problems' as the explanatory variable and the final adjusted model.

\section{Results}

\section{Characteristics of respondents}

There were 3632 school-going adolescents' data available for the current study. A total of 3227 responded to injury status questions. Of all school-aged adolescents who responded to the questionnaires, 53.2\% (1932) were boys and $45.8 \%$ (1662) were girls. The majority, $67.0 \%$ (2431) was $\leq 17$ years of age compared to $32.5 \%$ (1182) who were aged $18+$ years (Table 1$)$.

From a total of 3227 injury status respondents, $40.9 \%$ (1488) of school-aged adolescents reported having experienced a serious injury, whereas $47.9 \%$ (1739) reported no history of serious injury within the last 12 months. Among participants who reported serious injury, most of them reported home-related serious (64.5\%) injuries, with the least reported cause being traffic injuries (15.0\%). Furthermore, more than one-quarter reported multiple occurrences of serious injuries. Sixty-four percent of adolescents reported BMI classified as normal and $69.0 \%$ (2493) had physical activity at least once a day per week. More than half of the respondents reported a history of sleep-related problems and 63.2\% (2,295) had a history of loneliness (Table 1).

\section{Frequency of Injury by demographic factors}

The frequency of one injury in the last 12 months was $27.2 \%$, the prevalence of $2-3$ injuries and at least 4 or more injuries were $15.8 \%$ and $10.3 \%$ respectively. This frequency was not statistically significantly different between boys and girls $(p=0.368)$. Also, the possibility of reporting at least one injury in the past 12 months was significantly higher in adolescents aged $\leq 17$ than in those aged $\geq 18$ ( $p<0.001)$. Similarly, higher proportions of reporting at least one injury in the last 12 months were found among adolescents pursuing JHS education compared to SHS $(p<0.001)$. Likewise, differences were also observed among BMI groups $(p<0.015)$ (Table 2).

\section{Causes of Injury}

As shown in Table 3, higher proportions of causes of serious injury were found in adolescent respondents aged $\leq 17$ than in those $\geq 18$ ( $69.5 \%$ vs. $30.5 \%, p=0.039)$. In addition, the cause of serious injury was found to be statistically significantly different between girls and boys (47.7\% vs. $52.3 \%, \mathrm{p}<0.001)$. Implying that on average, the three major causes of injury were more common among boys compared to girls. Overall, SHS students had a higher proportion of all causes of serious injury compared to JHS students ( $52.8 \%$ vs. $47.2 \%, p=0.004)$. This result shows that most causes of serious injury (traffic and others) were higher in SHS students except for home injuries which were higher among JHS students. The results also revealed the cause of injury did not differ among BMI groups ( $p=0.508$ ) (Table 3 ).

Table 4 shows the results of both the unadjusted and adjusted association between unintentional injury and risk factors among school-going adolescents. The unadjusted results show that age, sex, education, and BMI were not statistically significantly associated with an unintentional injury. However, physical activity, sleep problems, and loneliness were found to be significantly associated with an unintentional injury. After adjusting for other factors, age was found to be significantly associated with unintentional injury; adolescents aged $\leq 17$ years were more likely to experience unintentional injuries compared to their counterparts aged $\geq 18$ years. In addition, adolescents who were physically active for at least one day per week for the past 7 days were 1.21 times $(p=0.025)$ more likely to experience unintentional injuries than those who did not. Moreover, adolescents who occasionally and frequently experienced sleep-related problems had, respectively, 1.55- and 1.85-times ( $\mathrm{p}<0.001$ ) higher odds of unintentional injuries compared to those who did not experience sleep-related problems. The latter findings also support a doseresponse relationship between sleep-related problems and unintentional injuries. Thus, non-problematic sleepers had lower odds of unintentional injuries than sometimes- or often-poor sleepers. Similarly, adolescents who occasionally and frequently experienced loneliness had, respectively, 1.19- and 1.81-times $(\mathrm{p}=0.003)$ higher odds of unintentional injuries compared to those who did not (Table 4).

Figure 1 portrays the ROC curves of a baseline model and a survey logistic model. The baseline model consists of age, physical activity, and loneliness whereas the survey logistic model consists of only sleep-related problems. The Area Under the Curve (AUC) for both the baseline model and the survey logistic model was 0.58 ( $A U C=0.58,95 \% \mathrm{Cl} 0.56-0.60)$. This indicates that sleep-related problems have a stronger influence 
on the association with unintentional injury than the three explanatory variables in the baseline model (age, physical activity, and loneliness) (See Fig. 1).

\section{Discussion}

This study explored the overall prevalence, frequency, causes, and associated risk factors of unintentional injuries among school-going adolescents in Ghana. We found that overall, (40.9\%) of sampled school-going adolescents experienced unintentional injuries in the last 12 months. Compared to findings from other low - and - middle-income countries, our finding is higher than what was found in Malaysia where a $34.9 \%$ unintentional injury prevalence was reported among the same population (Peltzer and Pengpid, 2015) but lower than other studies in Palestine (47.6\%) (Jildeh et al., 2013) and Nigeria (73.6\%) (Azubuike and Onyemaka, 2012) respectively.

This study also found that adolescents younger than 17 years of age were more likely to frequently report at least one or more injuries compared to those 18 + years. This finding is inline with the study conducted in Pakistan (Zia et al., 2012). The finding is also linked to an earlier finding in adolescent psychology that showed decreased impulsiveness and increase cognitive function as adolescents get older (Gao et al., 2019). Our study revealed that adolescents in JHS reported unintentional injuries more frequently compared to SHS students. This is in keeping with what was found in an Iranian study where elementary school students were more likely to frequently report injuries compared to high school students (Kelishadi et al., 2014). Our study did not find any statistical difference between boys and girls in terms of injury frequency.

In relation to causes of injuries, we found that many causes of injury were home-related (falls, something fell/hit me, assault/abuse, flame/something hot and poisoning). The result is consistent with a study conducted in Uganda that found, home-related injuries (burns and falls) as the major causes of injuries among adolescents (Ssemugabo et al., 2018). Secondly, compared to adolescents 17 years and younger, older adolescents (18 + years) were less likely to report all three major causes of injuries. This is coherent with the finding in Uganda (Ssemugabo et al., 2018). However, the result contrasts with a study conducted in Malaysia (Peltzer and Pengpid, 2015). Several explanations can be attributed to this finding. Firstly, overcrowding and informal settlements may predispose adolescents to home injuries such as falls and burns. Also, access to boiling liquids or fireplaces owing to open sources of cooking can lead to burn injuries at home. In addition, younger adolescents' inability to identify harmful substances (in case of poisonings) or anticipate dangers coupled with their inquisitiveness makes them susceptible to home injuries. There may also be opportunities to improve supervision, by informing parents and caregivers about potential dangers in the home or school environment. Hence, the need to intensify public awareness of the preventable nature of injuries at home and in schools.

Another major finding is that, on average, the main causes of injury (traffic, home, and others) were more common among boys than girls, although, home injuries were higher among girls compared to boys. The finding coincides with a recent Chinese study and may reflect differential exposure levels between boys and girls (Wu et al., 2019). An explanation for this finding may be that boys are socialized to be more adventurous and more likely to be engaged in activities that expose them to traffic and other injuries. Correspondingly, girls may be encouraged or required to take on more tasks and responsibilities in the home, which may expose them to heat sources of injury. Others have called for prioritizing adolescent boys in the planning and implementation of injury prevention and control strategies among school-aged adolescents (Granié, 2010), though in our study that would be specifically true for traffic injuries. In addition, our present findings indicate that traffic and other injuries were higher in SHS students while home injuries were higher among JHS students. Our finding is in line with what was earlier reported in a Chinese prospective cohort study (Alikhani, 2014).This may reflect similarities in the educational structure of the two countries. While most SHS students are residential, virtually all JHS students are non-residential. Also, the legal age to drive a car or a motorcycle in Ghana is $18+$ years. This may explain why traffic injuries are higher among SHS students who are within that age range compared to JHS students.

In our multivariable analysis, four risk factors of younger age, higher physical activity, sleep problems, and increased loneliness were associated with unintentional injuries among school-aged adolescents. We found that the odds of unintentional injuries were higher among adolescents aged $\leq 17$ years compared to those $\geq 18$ years. This finding agrees with several previous findings where younger age was a risk factor for adolescent injuries (Zagel et al., 2019, Fang et al., 2015, Gao et al., 2019).

One of our findings is that adolescents who engage in at least one Physical Activity (PA) for 60 minutes in a week were more likely to report injuries compared to those who do not. This result is consistent with those of previous studies (Peltzer and Pengpid, 2015, Räisänen et al., 2018). Despite this seeming disadvantage of PA, there are many other physical and mental health benefits to PA and it should continue to be promoted and geared toward encouraging adolescents to meet their PA guidelines. Such PA promotion should be focused on injury prevention and safe PA (Bloemers et al., 2012), for example, using bike helmets or similar safety equipment. Since literature is scarce regarding PA-related injuries among school-going adolescents in this setting, our finding provides valuable information for public health policy makers and may serve as a first step towards enhancing injury prevention efforts in Ghanaian schools.

Furthermore, we identified psychological distress factors of sleep problems and loneliness as independent risk factors of injuries. We found a significant association between a lack of sleep or sleep problems and injuries. Earlier studies have also reported similar results (Kim et al., 2015, Wu et al., 2019). Earlier researchers found that a person's cognitive and behavioral functioning is impacted by sleeplessness and fatigue, which 
in turn increases their risk of unintentional injuries (kim et.al.,2015, Tan et.al.,2015). The present study also revealed that adolescents who were often lonely were almost twice as likely to report unintentional injuries compared to those who were not. Our finding is in keeping with a recent study among school-going adolescents in Malaysia (Peltzer and Pengpid, 2015).

\section{Strengths And Limitations}

A major strength of this study is that no Ghanaian study explicitly explored the prevalence of unintentional injuries and their correlates among adolescents of school-going age and no known injury intervention programs exist in junior and senior high schools in the country. Therefore, a better understanding of the epidemiology of injury among adolescents of school-going age in Ghana would not only provide valueable information on the extent of injury problems in the country's educational sector but would help inform both prevention strategies and public policies. This study also used a substantial sample size and examined a less researched area that affects both the education and health wellbeing of adolescents in the country. There is also a limited evidence base among low- and - middle-income countries, thus studies like this one will help bridge that equity gap. Our study has a few limitations that should be noted. This study was limited to only school-going adolescents. Therefore, the findings may not be representative of the entire Ghanaian adolescent population. Also, the responses from this study were based on self-reports, therefore, recall or reporting bias is possible. Moreover, causality cannot be deduced from the associated factors we found due to the cross-sectional nature of the study design. Our analysis was restricted to those variables available in the Ghana GSHS study. Therefore, potential risk factors such as body part or location of injury could not be assessed. Finally, underestimation of unintentional injuries is possible, since the questionnaire captured only the most serious injuries spanning a 12-month recall period.

\section{Conclusion}

This study found that unintentional injuries were prevalent among Ghanaian school-going adolescents. In general, boys were disproportionately more likely to get injured, as were younger adolescents. Younger age, physical activity, sleep problems, and loneliness were the main risk factors for injuries among school-going adolescents in Ghana. Our findings should alert health policymakers, school administrators, and other stakeholders to institute school-based injury prevention strategies and make injury prevention in schools a public health priority. This can be done by incorporating school-based injury intervention programs into the Ghanaian educational system aimed at reducing unintentional injuries among school-going adolescents. Injury preventive measures should emphasize on boys in the context of traffic injuries and girls regarding home injuries as well as younger adolescents. Treatment options should be made available to adolescents struggling with psychological distress problems.

\section{List Of Abbreviations}

AUC- Area under the Curve

BMI- Body mass index

GSHS- Global School-based Student Health Survey

JHS -Junior High School

LMIC-Low and Middle-Income Countries

PA- Physical Activity

PSU- Primary Sampling Unit

ROC-Receiver Operating Characteristic

SHS - Senior High School

WHO-World Health Organization

\section{Declarations}

\section{Ethics approval and consent to participate}

Not applicable

\section{Acknowledgment}


The authors would like to acknowledge Dr. Catherine Trask for her expertise and assistance in shaping this manuscript.

Competing Interests: None declared

Funding: Authors did not receive funding for this study

\section{Authors' Contributions:}

SKE and BC conceptualized and designed the study. SKE and BC conducted the literature review and prepared the study data for analysis. SKE and $\mathrm{BC}$ conducted the statistical analysis, interpreted the results. SKE, BC and KGM wrote the draft manuscript. KGM revised the manuscript substantively for important intellectual content. KGM edited the manuscript to the final layout, formatted the manuscript to the journal's style, compiled final author edits to the manuscript, supporting materials and responsible as a corresponding author. All authors read and approved the final submitted version of the manuscript.

Consent for Publication: Not applicable

Availability of data and material

The dataset(s) supporting the conclusions of this article is available at https://www.who.int/ncds/surveillance/gshs/ghanadataset/en/

\section{References}

1. Agnelli, R. (2014). Examples of logistic modeling with the SURVEYLOGISTIC procedure. Proceedings of the SAS Global Forum Conference, SAS Global Forum, Washington, DC, Citeseer.

2. Alikhani, S., 2014. A profile of unintentional injuries among Iranian adolescents: findings from the first Health Behavior in School-Aged Children Survey. International Journal of School Health, 1(2), pp.1-5.

3. Allison, P. D. (2012). Logistic Regression Using SAS®: Theory and Application, Second Edition. , Cary, NC: SAS Institute Inc.

4. Azubuike, S.O. and Onyemaka, E.O. (2012). Epidemiology of non-fatal injuries among adolescents in an urban Niger delta community of Nigeria. International journal of critical illness and injury science, 2(3), p.180.

5. Bloemers, F., Collard, D., Paw, M.C.A., Van Mechelen, W., Twisk, J. and Verhagen, E. (2012). Physical inactivity is a risk factor for physical activity-related injuries in children. British journal of sports medicine, 46(9), pp.669-674.

6. CDC. (2018). Web-Based Injury Statistics Query and Reporting System (WISQARS); Centers for Disease Control and Prevention, National Center for Injury Prevention and Control: Atlanta, GA, USA. Available online: www.cdc.gov/wisqars (Accessed: 22 July 2020).

7. Cetin, D., Lessig, B.A. and Nasr, E.(2016). Comprehensive evaluation for obesity: Beyond body mass index. J. Am. Osteopath. Assoc, 116, pp.376-382.

8. Emery, C.A. and Pasanen, K. (2019). Current trends in sport injury prevention. Best Practice \& Research Clinical Rheumatology, 33(1), pp.315.

9. Fang, Y., Zhang, X., Chen, W., Lin, F., Yuan, M., Geng, Z., Yu, H. and Dai, L. (2015). Epidemiological characteristics and burden of childhood and adolescent injuries: a survey of elementary and secondary students in Xiamen, China. BMC public health, 15(1), p.357.

10. Gao, C., Chai, P., Lu, J., Wang, H., Li, L. and Zhou, X. (2019). Probing the psychosocial correlates of unintentional injuries among grade-school children: a comparison of urban and migrant students in China. Journal of child and family studies, 28(6), pp.1713-1723.

11. Gore, F.M., Bloem, P.J., Patton, G.C., Ferguson, J., Joseph, V., Coffey, C., Sawyer, S.M. and Mathers, C.D. (2011). Global burden of disease in young people aged 10-24 years: a systematic analysis. The Lancet, 377(9783), pp.2093-2102.

12. Granié, M.A. (2010). Gender stereotype conformity and age as determinants of preschoolers' injury-risk behaviors. Accident Analysis \& Prevention, 42(2), pp.726-733.

13. GSS. (2012) '2010 Population and housing census: Final results', Ghana statistical service, final results. Available at: https://www.statsghana.gov.gh/gssmain/storage/img/ marqueeupdater/Census2010_Summary_report_of_final_results.pdf.

14. Han, L., You, D., Gao, X., Duan, S., Hu, G., Wang, H., Liu, S. and Zeng, F. (2019). Unintentional Injury and Violence Among Adolescents in Lowand Middle-Income Countries. Available at SSRN 3337886.

15. Hosmer, D.W. and Lemeshow, S. (2000). Applied Logistic Regression, John Wiley \& Sons. New York.

16. Jildeh, C., Abdeen, Z., Al Sabbah, H. and Philalithis, A. (2013). Unintentional injuries among school-aged children in Palestine: findings from the National Study of Palestinian Schoolchildren (HBSC-WBG2006). International Journal of Population Research, 2013, pp.1-7.

17. Kelishadi, R., Qorbani, M., Motlagh, M.E., Ardalan, G., Moafi, M, Mahmood-Arabi, M., Heshmat, R. and Jari, M. (2014). Frequency, causes, and places of unintentional injuries in a nationally representative sample of Iranian children and adolescents: the CASPIAN-IV

Page $7 / 14$ 
study. International journal of preventive medicine, 5(10), p.1224.

18. Kim, S.Y., Sim, S., Kim, S.G. and Choi, H.G. (2015). Sleep deprivation is associated with bicycle accidents and slip and fall injuries in Korean adolescents. PLoS One, 10(8), p.e0135753.

19. McHugh, M.L. (2013). The chi-square test of independence. Biochemia medica: Biochemia medica, 23(2), pp.143-149. Available at:

20. https://www.biochemia-medica.com/en/journal/23/2/10.11613/BM.2013.018

21. Omaki, E., Rizzutti, N., Shields, W., Zhu, J., McDonald, E., Stevens, M.W. and Gielen, A. (2017). A systematic review of technology-based interventions for unintentional injury prevention education and behaviour change. Injury prevention, 23(2), pp.138-146.

22. Orton, E., Whitehead, J., Mhizha-Murira, J., Clarkson, M., Watson, M.C., Mulvaney, C.A., Staniforth, J.U., Bhuchar, M. and Kendrick, D. (2016). School-based education programmes for the prevention of unintentional injuries in children and young people. Cochrane database of systematic reviews, (12).

23. Owusu, A., 2008. Global School-Based Student Health Survey (GSHS) (2008): Ghana Report Senior High Schools: Middle Tennesse State University. WHO, CDC, GES.

24. Peltzer, K. and Pengpid, S. (2015). Unintentional injuries and psychosocial correlates among in-school adolescents in Malaysia. International journal of environmental research and public health, 12(11), pp.14936-14947.

25. Porter, M.A., Lilli, A.N.C. and Schellinger, C.N. (2019). The burden of unintentional injury mortality among American Indians/Alaska Natives in Michigan, Minnesota, and Wisconsin. Journal of public health management and practice, 25, pp.S20-S28.

26. Posner, M. (2000). Preventing school injuries: A comprehensive guide for school administrators, teachers, and staff. Rutgers University Press.

27. Ralaidovy, A.H., Bachani, A.M., Lauer, J.A., Lai, T. and Chisholm, D. (2018). Cost-effectiveness of strategies to prevent road traffic injuries in eastern sub-Saharan Africa and Southeast Asia: new results from WHO-CHOICE. Cost effectiveness and resource allocation, 16(1), p.59.

28. Räisänen, A.M., Kokko, S., Pasanen, K., Leppänen, M., Rimpelä, A., Villberg, J. and Parkkari, J. (2018). Prevalence of adolescent physical activity-related injuries in sports, leisure time, and school: the National Physical Activity Behaviour Study for children and Adolescents. BMC musculoskeletal disorders, 19(1), pp.1-8.

29. Salam, R.A., Arshad, A., Das, J.K., Khan, M.N., Mahmood, W., Freedman, S.B. and Bhutta, Z.A. (2016). Interventions to prevent unintentional injuries among adolescents: A systematic review and meta-analysis. Journal of Adolescent Health, 59(4), pp.S76-S87.

30. Shinsugi, C., Stickley, A., Konishi, S., Ng, C.F.S. and Watanabe, C. (2015). Seasonality of child and adolescent injury mortality in Japan, 2000-2010. Environmental health and preventive medicine, 20(1), pp.36-43.

31. Sleet, D.A., Ballesteros, M.F. and Borse, N.N. (2010). A review of unintentional injuries in adolescents. Annual review of public health, 31, pp.195-212.

32. Sleet, D. A. (2018). The global challenge of child injury prevention. Multidisciplinary Digital Publishing Institute.

33. Ssemugabo, C., Mukama, T., Halage, A.A., Paichadze, N., Gibson, D.G. and Kobusingye, O. (2018). Incidence and characteristics of unintentional injuries among children in a resource limited setting in Kampala, Uganda. International journal of injury control and safety promotion, 25(4), pp.449-457.

34. Street, E. J., \& Jacobsen, K. H. (2016). Injury incidence among middle school students aged 13-15 years in 47 low-income and middleincome countries. Injury Prevention, 22, 432-436

35. Tan, Y., Ma, D., Chen, Y., Cheng, F., Liu, X. and Li, L. (2015). Relationships between sleep behaviors and unintentional injury in southern Chinese school-aged children: a population-based study. International journal of environmental research and public health, 12(10), pp.12999-13015.

36. Children's Safety Network \& National Institute for Health Care Management (2010). Preventing adolescent injury: The role of health plans. CSN/NIHCM Issue Brief; Apr. pp. 1-6. Available at: https://www.google.com/search?client=firefoxbd\&q=10.\%09The+Children's+Safety+Network+\%28CSN\%29+and+National+Institute+for+Health+Care+Management+\%28NIHCM\%29+2010 (Accessed: 22 July 2020).

37. Vecino-Ortiz, A.I., Jafri, A. and Hyder, A.A. (2018). Effective interventions for unintentional injuries: a systematic review and mortality impact assessment among the poorest billion. The Lancet Global Health, 6(5), pp.e523-e534.

38. WHO. (2009). Global health risks: Mortality and burden of disease attributable to selected major risks. World Health Organization. https://apps.who.int/iris/handle/10665/44203. (accessed 10 April 2020).

39. WHO. (2012). Ghana-Global School-based Student Health Survey (GSHS).

https://extranet.who.int/ncdsmicrodata/index.php/catalog/422/study-description\#page=sampling\&tab=study-desc. [Accessed 9 May 2020]

40. WHO. (2013). Global School-based Student Health Survey. GSHS Data User's Guidehttps://www.cdc.gov/gshs/background/pdf/gshs-datausers-guide.pdf. (Accessed 10 May 2020). 
41. WHO.(2015). Children's environmental health: Injuries. Available at: https://www.google.com/search?client=firefox-b $\mathrm{d} \& \mathrm{q}=8 . \% 09 \mathrm{WHO} .+$ Children's+environmental+health\%3A+Injuries (Accessed 10 April 2020).

42. WHO. (2018). Injury-related disability and rehabilitation. Retrieved from https://www.who.int/violence_injury_prevention/disability/en//. (Accessed 10 April 2020).

43. WHO. (2020). Global school-based student health survey (GSHS). URL: https://www. who. int/ncds/surveillance/gshs/en/(Accessed 10 April 2020).

44. WHO.(2020). Global School-based Student Health Survey (GSHS). Purpose and Methodology. https://www.who.int/ncds/surveillance/gshs/methodology/en/.( Accessed 9 May 2020).

45. WHO (2008). World report on child injury prevention. World Health Organization [https://apps.who.int/iris/bitstream/handle/10665/43851/9789241563574_eng.pdf;jsessionid=38F3326D38F6F411B82CFAB8A1A0941C? sequence=1/] (Accessed 10 July 2020).

46. Wu, D., Yang, T., Cottrell, R.R., Zhou, H. and Feng, X. (2019). Prevalence and behavioural associations of unintentional injuries among Chinese college students: a 50-University population-based study. Injury prevention, 25(1), pp.52-59.

47. Zagel, A.L., Cutler, G.J., Linabery, A.M., Spaulding, A.B. and Kharbanda, A.B. (2019). Unintentional Injuries in Primary and Secondary Schools in the United States, 2001-2013. Journal of School Health, 89(1), pp.38-47.

48. Zia, N., Khan, U.R., Razzak, J.A., Puvanachandra, P. and Hyder, A.A. (2012). Understanding unintentional childhood home injuries: pilot surveillance data from Karachi, Pakistan. BMC research notes, 5(1), p.37.

\section{Tables}


Table 1

Characteristics and distribution of the study population $(\mathrm{N}=3632)$

\section{Variables}

Injury Status (12 months)

No

Yes

Cause of Injury*

Traffic

Home

Other

Injury Frequency (12 months)

Zero

1 time

2-3 times

$\geq 4$ times

Age/year

$\leq 17$

$\geq 18$

Gender

Girls

Boys

\section{Education}

Junior High School

Senior High School

BMI

Normal (18.5-24.9)

Underweight $(<18.5)$

Pre-obese (25-29.9)

Obese $(\geq 30)$

\section{Physical Activity}

None

At least a day

Sleep Problems

Never

Sometimes

Often

Loneliness

Never

*Missing values are not displayed in this table, but are as follows: injury status 405 (11.2\%); injury frequency 540 (14.9\%); Age 19 (0.5\%); Gender 38 (1.0\%); Education 15 (0.4\%); BMI 184 (5.1\%); Physical Activity 38 (1.1\%); Sleep Problems 15 (0.4\%) and Loneliness 14 (0.4\%

*Cause of injury for those who responded yes to injury status and excluded those who responded no injury
$\%$

47.9

40.9

223

15.0

959

64.5

306

20.5

1154

31.8

989

27.2

575

15.8

374

10.3

2431

67.0

1182

32.5

1662

45.8

1932

53.2

1645

45.3

1972

54.3

2317

63.8

$938 \quad 25.8$

167

4.6

26

0.7

$1101 \quad 30.3$

2493

68.6

1554

42.8

1533

42.8

530

14.6

1323

36.4 


\begin{tabular}{|l|c|}
\hline Variables & N \\
\hline Sometimes & 1713 \\
\hline Often & 582 \\
\hline $\begin{array}{l}\text { *Missing values are not displayed in this table, but are as follows: injury status 405 (11.2\%); injury frequency 540 (14.9\%); Age 19 (0.5\%); } \\
\text { Gender 38 (1.0\%); Education 15 (0.4\%); BMI 184 (5.1\%); Physical Activity 38 (1.1\%); Sleep Problems 15 (0.4\%) and Loneliness 14 (0.4\% }\end{array}$ \\
\hline *Cause of injury for those who responded yes to injury status and excluded those who responded no injury \\
\hline
\end{tabular}

Table 2

Frequency of injuries during the last 12 months by age, sex, educational level, and body mass index

\begin{tabular}{|c|c|c|c|c|c|}
\hline \multirow[t]{2}{*}{ Variables } & \multicolumn{4}{|c|}{ Injury Frequency N (\%) } & \multirow[t]{2}{*}{ P-values } \\
\hline & Zero & 1 time & 2-3 times & $\geq 4$ times & \\
\hline Age/year & & & & & $<0.001$ \\
\hline$\leq 17$ & $681(22.1 \%)$ & $710(23.1 \%)$ & 401(13.1\%) & $264(8.6 \%)$ & \\
\hline$\geq 18$ & $468(15.2 \%)$ & $275(8.9 \%)$ & $170(5.5 \%)$ & $108(3.5 \%)$ & \\
\hline Gender & & & & & 0.368 \\
\hline Girls & $509(16.6 \%)$ & $467(15.3 \%)$ & $261(8.5 \%)$ & $165(5.4 \%)$ & \\
\hline Boys & $640(20.9 \%)$ & $509(16.6 \%)$ & $305(10.0 \%)$ & $206(6.7 \%)$ & \\
\hline Education & & & & & $<0.001$ \\
\hline Junior High School & $380(12.3 \%)$ & $498(16.2 \%)$ & $290(9.4 \%)$ & $206(6.6 \%)$ & \\
\hline Senior High School & $769(25.0 \%)$ & $490(15.9 \%)$ & $282(9.2 \%)$ & $165(5.4 \%)$ & \\
\hline BMI & & & & & 0.015 \\
\hline Normal (18.5-24.9) & $775(26.4 \%)$ & $614(20.9 \%)$ & $356(12.1 \%)$ & $239(8.1 \%)$ & \\
\hline Underweight $(<18.5)$ & $269(9.2 \%)$ & $268(9.1 \%)$ & $169(5.7 \%)$ & $95(3.2 \%)$ & \\
\hline Pre-obese (25-29.9) & $53(1.8 \%)$ & $49(1.7 \%)$ & $15(0.5 \%)$ & $14(0.5 \%)$ & \\
\hline Obese $(\geq 30)$ & $8(0.3 \%)$ & $11(0.4 \%)$ & $4(0.1 \%)$ & $1(0.0 \%)$ & \\
\hline
\end{tabular}


Table 3

Causes of injuries during the last 12 months by age, sex, educational level, and body mass index

\begin{tabular}{|lllll|}
\hline Variables & \multicolumn{2}{l}{ Cause of Injury N (\%) } & P-values \\
\cline { 2 - 4 } & Traffic & Home & Other & \\
\hline Age/year & & & 0.039 \\
\hline$\leq 17$ & $138(9.3 \%)$ & $693(46.8 \%)$ & $198(13.4 \%)$ & \\
\hline$\geq 18$ & $82(5.5 \%)$ & $262(17.7 \%)$ & $108(7.3 \%)$ & \\
\hline Gender & & & & $<0.001$ \\
\hline Girls & $68(4.6 \%)$ & $482(32.7 \%)$ & $153(10.4 \%)$ & \\
\hline Boys & $151(10.2 \%)$ & $470(31.8 \%)$ & $152(10.3 \%)$ & \\
\hline Education & & & & 0.004 \\
\hline Junior High School & $108(7.3 \%)$ & $501(33.8 \%)$ & $91(6.1 \%)$ & \\
\hline Senior High School & $112(7.6 \%)$ & $455(30.7 \%)$ & $214(14.5 \%)$ & \\
\hline BMl & & & & 0.508 \\
\hline Normal (18.5-24.9) & $145(10.3 \%)$ & $606(42.9 \%)$ & $196(13.8 \%)$ & \\
\hline Underweight (<18.5) & $52(3.7 \%)$ & $255(18.1 \%)$ & $77(5.4 \%)$ & \\
\hline Pre-obese (25-29.9) & $8(0.6 \%)$ & $43(3.0 \%)$ & $18(1.3 \%)$ & \\
\hline Obese ( $\geq 30)$ & $0(0.0 \%)$ & $11(0.8 \%)$ & $2(0.1 \%)$ & \\
\hline
\end{tabular}


Table 4

Unadjusted and adjusted models showing the association between unintentional injuries and risk factors among adolescents

\begin{tabular}{|c|c|c|c|c|c|c|}
\hline \multirow[t]{2}{*}{ Variables } & \multicolumn{3}{|c|}{ Unadjusted Analysis } & \multicolumn{3}{|c|}{ Adjusted Analysis } \\
\hline & UOR & $95 \% \mathrm{Cl}$ & P-values & AOR & $95 \% \mathrm{Cl}$ & P-values \\
\hline Age/year & & & 0.170 & & & 0.012 \\
\hline$\leq 17$ & 1.00 & & & 1.00 & & \\
\hline$\geq 18$ & 0.88 & $(0.73-1.07)$ & & 0.76 & $(0.62-0.93)$ & \\
\hline Gender & & & 0.593 & & & \\
\hline Girls & 1.00 & & & & & \\
\hline Boys & 0.96 & $(0.82-1.13)$ & & & & \\
\hline Education & & & 0.507 & & & \\
\hline Junior High School & 1.00 & & & & & \\
\hline Senior High School & 0.93 & $(0.74-1.17)$ & & & & \\
\hline BMI & & & 0.743 & & & \\
\hline Normal (18.5-24.9) & 1.00 & & & & & \\
\hline Underweight $(<18.5)$ & 1.06 & $(0.89-1.24)$ & & & & \\
\hline Obese* $^{\star}(25-\geq 30)$ & 1.03 & $(0.74-1.42)$ & & & & \\
\hline Physical Activity & & & 0.009 & & & 0.025 \\
\hline None & 1.00 & & & 1.00 & & \\
\hline At least a day & 1.23 & $(1.06-1.43)$ & & 1.21 & $(1.03-1.43)$ & \\
\hline Sleep Problems & & & $<0.001$ & & & $<0.001$ \\
\hline Never & 1.00 & & & 1.00 & & \\
\hline Sometimes & 1.59 & $(1.29-1.96)$ & & 1.55 & $(1.21-1.99)$ & \\
\hline Often & 2.03 & $(1.68-2.46)$ & & 1.85 & $(1.46-2.36)$ & \\
\hline Loneliness & & & $<0.001$ & & & 0.003 \\
\hline Never & 1.00 & & & 1.00 & & \\
\hline Sometimes & 1.29 & $(1.02-1.62)$ & & 1.19 & $(0.93-1.53)$ & \\
\hline Often & 2.18 & $(1.69-2.78)$ & & 1.81 & $(1.35-2.42)$ & \\
\hline
\end{tabular}

\section{Figures}




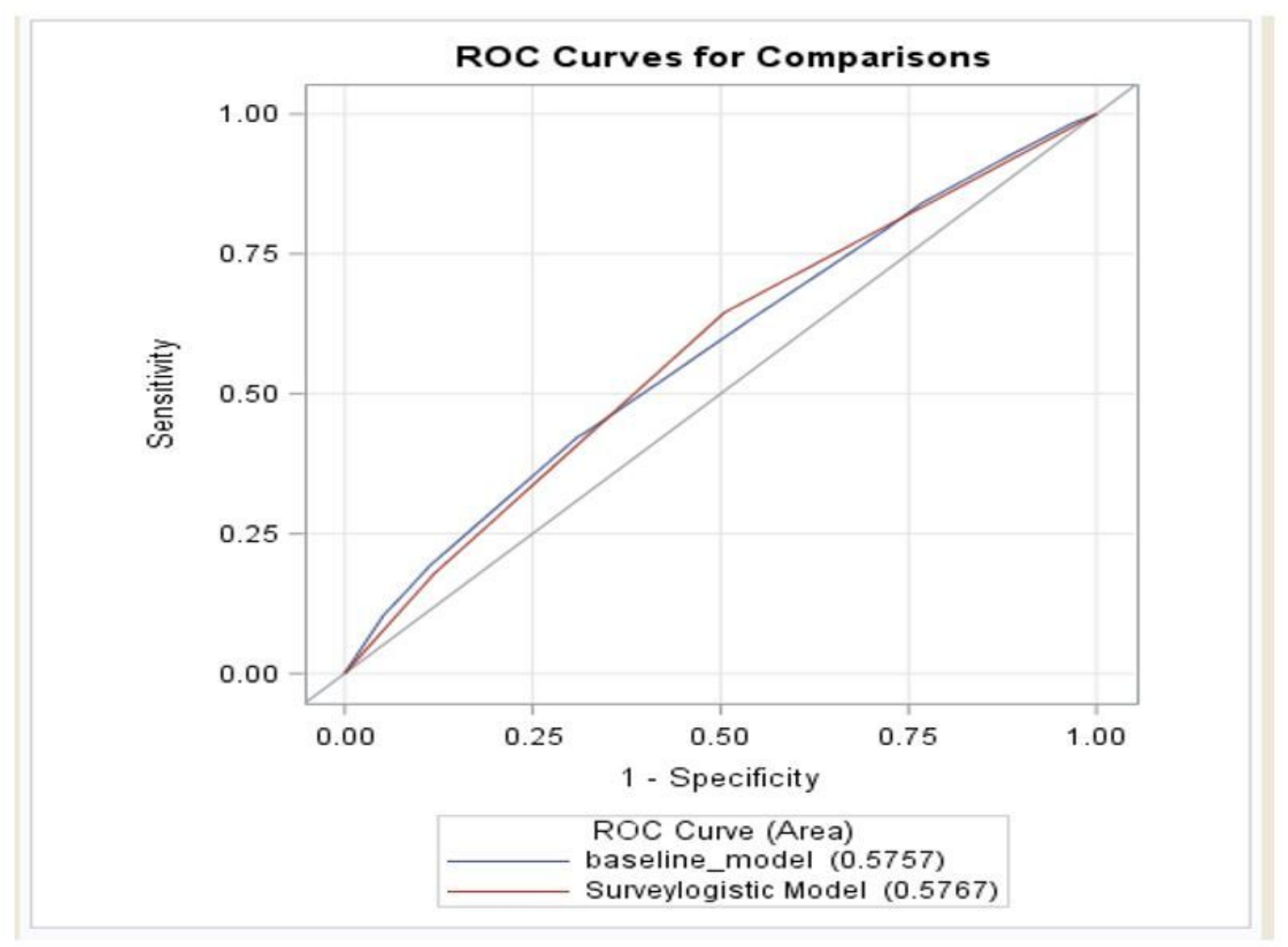

Figure 1

ROC curve comparing the influence of a baseline model with age, physical activity and loneliness and a model with only sleep problems on unintentional injury 